УДК 37

DOI $10.21661 / \mathrm{r}-130001$

\title{
И.А. Чекин
}

\section{НЕКОТОРЫЕ ВОПРОСЫ ОБРАЗОВАТЕЛЬНО-РОЛЕВОЙ МОДЕЛИ ИНФОРМАЦИОННОГО СОПРОВОЖДЕНИЯ ОБРАЗОВАНИЯ ВЗРОСЛЫХ}

Аннотация: статья поднимает некоторые вопросы методологических основ реализации образовательно-ролевой модели информационного сопровождения образования взрослых в контексте адаптационно-ролевого резонанса. Автор раскрывает основные принципы, на которых базируется процесс реализации образовательно-ролевой модели. Говоря о своеобразии образовательно-ролевой модели, он подчеркивает, что сенсуальная очевидность образовательноролевой модели условна, фрагментарна и играет вспомогательную роль. При формировании образовательно-ролевой модели информаџионного сопровождения образования взрослых, считает исследователь, особое внимание должно уделяться ее гносеологической емкости.

Ключевые слова: личность, принципы изучения личности, образовательноролевая модель, адаптационно-ролевой резонанс, информационное сопровождение, образование взрослых, смысловое пространство, сенсуальность, идеал, гносеологическая емкость, сочиальное регулирование, сочиальный образ.

\section{I.A. Chekin}

\section{SOME QUESTIONS ON EDUCATIONAL AND ROLE MODEL OF INFORMATION SUPPORT FOR ADULT EDUCATION}

Abstract: the article discusses some questions on methodological basis of educational and role model implementation of information support for adult education in the context of adaptation and role resonance. The author reveals the main principles on which the process of the educational and role model realization is based. Speaking of the educational and role model individuality he stresses that sensual obviousness of 
the educational and role model is relative, fragmentary and it plays a support role. According to the author it is important to pay much attention to gnoseological capacity of the educational and role model during the process of information support of adult education.

Keywords: individuality, principles of character research, educational and role model, adaptation and role resonance, information support, adult education, conceptual area, sensual, ideal, gnoseological capacity, social regulation, social image.

Проблема образовательно-ролевой модели, ее разрешение связаны не просто с жизнедеятельностью взрослого человека, а с жизнью и деятельностью личности взрослого человека. В свою очередь эта связь предполагает объективную необходимость рассмотрения личности взрослого человека в контексте образовательно-ролевой модели и адаптационно-ролевого резонанса.

Личность - сложнейшая естественная система, совмещающая в себе биологические и социальные, сознательные и бессознательные, разумные (логические) и образные подсистемы, но не сводящаяся ни к одной из них и обладающая собственной неповторимой совокупностью системных качеств. В процессе становления личности совершаются отдельные прорывы в то или иное новое системное свойство, но происходит это неравномерно, не одновременно во всех подсисте$\max [7$, c. 132].

Рассмотрение вопросов образовательно-ролевой модели вытекает из разрешения следующей проблемы: возможна ли потребность в образовательно-ролевой модели, а вслед за ней обретение смысла жизни «внутри» повседневности? Если верно утверждение, что продуктивная, сознательная, приносящая плоды, утверждающая в человеке чувство хозяина своей судьбы деятельность порождает у него уверенность в полноте бытия, то принятие взрослым человеком образовательно-ролевой модели и, в свою очередь адаптационно-ролевой резонанс порождают у него ощущение жизненной опоры, помогает взрослому человеку приобрести смысл своей жизнедеятельности. 
Реализачия образовательно-ролевой модели информационного сопровождения образования взросльх - это процесс формирования личности взрослого человека через образовательно-ролевую модель. Формирование в его всеобщем значении - это развитие чего-либо под влиянием целенаправленных на него воздействий. Однако понятие «формирование личности» содержит и то особенное, что в его специфических для личности видах может быть правильно понято только в свете теории отражения.

Специфическое для личности формирование - это целенаправленное обогащение ее содержательной стороны путем превращения отражаемой реальности, лежащей вне этих рамок, в отраженное, входящее в ее рамки, т.е. беспрерывное присвоение мира ею. Есть три основных пути формирования личности: стихийное, целенаправленное и самоформирование.

По нашему мнению, процесс реализации образовательно-ролевой модели информационного сопровождения образования взрослых базируется на основных принципах изучения личности, сформулированных К.К.Платоновым в работе «Структура и развитие личности», а именно:

1. Принцип целенаправленного изучения личности.

2. Принцип изучения единства личности.

3. Принцип комплексности изучения.

4. Принцип объективности изучения.

5. Принции динамичности изучения.

В условиях социально-экономической и духовной нестабильности успешность выживания личности определяется не только материальным благополучием, но, прежде всего, наличием у взрослого человека духовного стержня, его созидательного потенциала, повышающего способность индивида к выживанию и психологической самозащите.

Стремление избежать диссонанса - есть, прежде всего, стремление к сохранению устойчивости сложившейся когнитивной системы. Но развитие когнитивной сферы личности предполагает постоянное обогащение и преобразование имеющейся системы знаний и взглядов. Наряду со стремлением к стабильности 
установочных структур, для человека характерно и стремление к новому, не укладывающемуся в рамки ранее сформированных схем.

Многие ученые и практики видят выход из кризиса, в котором находится наше общество, - в обретении новой системы ценностей, новой ценностной ориентации. Именно в образовании, нередко, латентным образом, происходит «конструирование» системы ценностных ориентаций, происходит «обмен» ценностями. Смысловое пространство изенностей создается информационным сопровождением образования. Ценностные ориентации взрослого человека служат глубинным регулятором его действий: с одной стороны, они могут быть случайным тормозом выхода из адаптационного синдрома, а с другой стороны - побудительным мотивом к оптимальной адаптации в новых социально-экономических условиях, нравственных и культурно-профессиональных отношениях.

Идея ценностной ориентации находит свое философско-психологическое обоснование в трудах многих наших ученых о высшем смысле человеческой жизни, «самотрансцендентности» как социально обусловленной потребности цивилизованного человека к постоянному «выходу» за пределы потребностей своего собственного «Я» в целях постижения субъективной сущности других и достижения общих благ (А.А. Брудный, С.Г. Вершловский, С.П. Иванова, Д.А. Леонтьев, М. Маслоу, В.А. Петровсий, Г.С. Сухобская, Э. Фромм и др.).

С.Г. Вершловский считает, что разработка и реализация образовательно-ролевой модели как средства адаптации взрослого человека к новым социальноэкономическим условиям детерминированы его жизненными кризисами и этапами развития [6, с. 178].

Поводом для кризиса обычно бывает вмешательство случая, который всегда готов проявиться в хаосе обыденной жизни. Какая-то из случайностей может оказать мощное резонансное воздействие на личность и тем самым заставить ее принять решение о выборе нового направления развития. Однако случай не только провоцирует кризис, он и консолидирует систему моделей: «встряхивая» ее, он заставляет все подсистемы выстраиваться в силовом поле целостности. Кризисы, повергая личность в состояние тяжелого затруднения и растерянности, 
помогают ей определить свои самые глубокие, самые насущные ценности и интересы. Кризис - это не крах, он предвещает перестройку и усовершенствование системы моделей личности.

При движении к зрелости происходит внутреннее согласование опыта, нарастает целостность индивидуальной культуры, устанавливается единое (при внутреннем многообразии) мировоззрение. Бывает, приходит и мудрость - это замечательное соединение знания с пониманием и терпимостью, с готовностью выслушать иную точку зрения и ждать от каждой новой встречи приращения своего образования. На пути к зрелости можно выделить три крупных этапа, из которых складывается путь личности - в частности, они проходятся при освоении любой новой области деятельности: 1) самоутверждение; 2) самореализация; 3) постижение смысла.

Говоря о необходимости и важности реализации образовательно-ролевой модели, как средства адаптации взрослого человека к новым социально-экономическим условиям, мы отдаем себе отчет в том, что ни сам андрагог, ни сам формирующийся взрослый человек не могут абсолютно знать заранее, какая именно «встреча» в жизни окажется значимой, какое воздействие может привести взрослого человека, обучаемого к адаптационно-ролевому резонансу, «резонансному отклику» [5, с. 203]. Это обусловлено тем, что процесс образования всегда ограничен теми возможностями, которые представляет данная культурная ниша, а личность всегда бессознательно стремится находить в многообразии внешнего окружения нишу для роста души. Никто никогда не узнает, какие возможности развития личности оказались упущенными из-за отсутствия в окружении соответствующего материала.

Под образовательно-ролевой моделью мы понимаем индивидуальную культуру взрослого человека, включающую в себя характер, нравы, обычаи, привычки; сознание и самосознание; знания, умения, навыки; интеллект и чувства; цุелостную систему представлений об окружающем мире объективно необходимые для оптимальной адаптации взрослого человека к новым сочуиально-экономическим условиям. Чем более разнообразна культура сообщества, тем больше 
возможностей у взрослого человека свободно строить универсальную культуру, свою жизнедеятельность. Информационное сопровождение образования взрослых соединяет взрослого человека с культурой сообщества, она задает контекст любому личному совершенствованию, личному свершению. Другими словами, образовательно-ролевая модель - идеальное образование, с помощьюю которого предполагается осуществить управление жизнью взрослого человека посредством его адаптации к новым социально-экономическим условиям. Образовательно-ролевая модель как идеальное образование находит свое отражение в образовательно-ролевой модели информационного сопровождения образования взрослых. Поэтому можно говорить об образовательно-ролевой модели информационного сопровождения образования взросльх.

В центре внимания информационного сопровождения образования взрослых, ориентированного на созидание образовательно-ролевой модели, находится внутренний мир человека: его мысли, переживания, ценности, потребности и т. п. Исходя из вышесказанного, информационное сопровождение образования взрослых при формировании образовательно-ролевой модели призвано, говоря словами А. Шопенгауэра, «извлечь из данной нам личности возможно большую выгоду, иными словами - гнаться лишь за отвечающими ей целями и заботиться лишь о такого рода развитии, которое как раз к ней подходит, избегая всякого другого, избирая, следовательно, сообразное с ней положение, занятие и образ жизни» $[11$, с. 232]. Образовательно-ролевая модель, освобожденная от академической элитарности и профессионально-социальной условности, предназначена для индивидуального и группового потребления. Образовательно-ролевая модель есть воплощение, с помощью информационного сопровождения образования взрослых, сложной системы отражения действительности: с одной стороны, конкретные срезы конкретно-исторической реальности, с другой - мировоззрение, внутренний мир взрослого человека.

Своеобразием образовательно-ролевой модели является ее наглядность. Наглядность вовсе не претендует на иллюстративное изображение изучаемого среза действительности. И хотя наглядность образовательно-ролевой модели не 
сводится к зрительным ассоциациям, все-таки в ней имеется частичная визуализация. Но, следует отметить, что сенсуальная очевидность образовательно-ролевой модели условна, фрагментарна и играет вспомогательную роль в абстрактнологическом изложении образовательно-ролевой модели.

При формировании образовательно-ролевой модели информационного сопровождения образования взрослых необходимо решать кардинальный вопрос о ее гносеологической «емкости»: сколько срезов и аспектов объективной реальности должно быть воспроизведено в модели, чтобы взрослый человек мог оптимально адаптироваться к новым социально-экономическим условиям. По нашему мнению, процесс реализации образовательно-ролевой модели информационного сопровождения образования взрослых и стратегии образовательно-ролевого резонанса есть один из путей достижения акме, а образовательно-ролевая модель информационного сопровождения образования взрослых - одна из разновидностей акме-моделей: одновершинная модель; многовершинная модель; макровершинная модель; безжизненная модель. Иначе говоря, образовательноролевая модель выступает в виде идеала, к которому стремится взрослый человек, включенный в непрерывное образование.

Поскольку способов идеализации одного и того же явления может существовать очень много, а с другой стороны, это явление не совпадает со своей сущностью, то возникает следующий вопрос: нельзя ли выбрать такой способ идеализации, при котором явление в результате описанного выше предельного перехода совпало бы со всей сущностью? Так как ни у одного реального объекта явление не совпадает с сущностью, то достичь такого совпадения, по всей вероятности, можно только путем искусственной идеализации объекта, т.е. в некотором пределе - «идеале».

Таким образом, понятие идеала в нашем случае, (образовательно-ролевая модель), приобретает новую черту: это не просто предельное представление, а такое, содержанием которого оказывается явление, совпадающее с собственной сущностью. Говоря более простым языком, можно сказать, что идеал - это явление, очищенное от всего того, что маскирует его сущность. В таком «очищении» 
и состоит смысл идеализации. Так как при «устремлении к нулю» результат идеализации в общем случае не совпадает ни с одним из компонентов исходного явления, а есть нечто качественно новое. Последнее особенно ярко проявляется в том, что идеал может сочетать такие признаки, которые в реальных объектах являются взаимоисключающими.

Когда андрагог в образовательно-ролевой модели (идеале) подвергает идеализации определенное явление (роль, статус), то он всегда представляет в модели (идеале) сущность явления (роли, статуса) в собственной интерпретации. Это значит, что из множества возможных способов идеализации одного и того же явления он выбирает такой, который «очищает» это явление от всего того, что маскирует сущность в его понимании. Не трудно догадаться, что в отличие от явления, которое оказывается предметом знания, понятие о предполагаемой сущности обычно диктуется не знанием объективной сущности, а желанием, чтобы она была именно такой, какой мы ее хотим видеть (стремление выдать желаемое за действительное). Вот почему противопоставление объекта, каким он является, объекту, каким бы мы его хотели видеть, связано, в конечном счете, с противопоставлением явления и сущности. Стало быть, идеал есть предельное представление, содержанием которого оказывается явление, совпадающее с сущностью в авторской интерпретации.

Для информационного сопровождения образования взрослых образовательно-ролевая модель - это не самоцель, а средство усиления возможностей, способностей взрослого человека, формирования у него разных типов творческой деятельности, вооружение конкретными способами самообразования и самосозидания, умением и навыками решения профессиональных и непрофессиональных задач.

В идеале образовательно-ролевая модель информационного сопровождения образования взросльх совпадает с образовательно-ролевой моделью жизни и деятельности взрослого человека. Объективная необходимость формирования информационным сопровождением образования взрослых образовательно-ролевой модели жизни и деятельности обусловлена тем, «что поведение и деятельность 
человека, - отмечает Г.Л. Тульчинский, - ориентированы на общественно заданные образцы, эталоны и нормы, что в свою очередь связано с необходимостью социального регулирования поведения индивидов данного сообщества и с систематической передачей накопленного им опыта жизнедеятельности» [9, с. 372].

Образовательно-ролевая модель как идеал представляет собой некоторую конструкцию из очень желаемых цзенностей. Такая конструкция может быть намечена схематически, поскольку является результатом заострения в воображении черт подлинной реальности. И взрослый человек нередко отдает себе отчет в том, что вероятность осуществления идеала мала, но желательность его настолько велика, что стремление к идеалу (образовательно-ролевой модели), сознательное или бессознательное, происходит постоянно. Иногда приходиться обманываться, принимая за воплощение идеала нечто сходное с ним лишь по несущественным признакам.

В связи со сказанным, образовательно-ролевая модель - это, на наш взгляд, ориентирующееся самобытие. Это обусловлено тем, что образовательно-ролевая модель - обобществленная типизация, и в ней, естественно, по сравнению с конкретной социально-экономической ситуацией многого будет недоставать и многое другое будет добавляться, не достигая завершенного образа. Но образовательно-ролевая модель, будущий социальный образ взрослого человека, служит импульсом, который заставляет индивида вновь обращаться к тому, что, по существу, и имеет значение для взрослого человека. Понимая, что образовательноролевая модель - это не замкнутый образ, и никогда он не будет завершенным, то всякая ее абсолютизация опасна. Здесь необходимо отметить, что если и предполагается возможность распада образовательно-ролевой модели, то лишь до той грани, за которой становится видимым начало формирования, необходимость и возможность создания новой. Только такое понимание информационного сопровождения образования взрослых образовательно-ролевой модели ставит его на экзистенциональную основу.

Если информационное сопровождение образования взрослых не может предсказать поведение индивида на длительное время, то оно вполне может 
предсказать общие тенденции, выработать главную политику, стратегию действия, оставляя детали на долю самоорганизации, саморазвития взрослого человека.

\section{Список литературы}

1. Алексеев С.А. Некоторые проблемы образования взрослого незанятого населения // Проблемы образования андрагогической компетентности специалистов постдипломного образования: Материалы второй международной научнопрактической конференции кафедры педагогики и андрагогики (16-17 апреля 2002 г.). - СПб., 2002. - С.18.

2. Андрагогика: образовательная программа / С.-Петерб. акад. постдиплом. пед. образования, каф. педагогики и андрагогики; науч. ред.: С.Г. Вершловский]. - СПб.: Санкт-Петербургская академия постдипломного педагогического образования, 2004. - 26 с.

3. Башарина Л.А. Информационные технологии: Эволюция к новому качеству. - Социализация взрослых: Учебн. пособие. - СПб.: Спец. Лит, 2002 - 272 с.

4. Бердяев Н.А. Философия свободы: Сборник / Н. Бердяев. - Харьков: АСТ; Фолио, 2002. - 732 с.

5. Бранский В.П. Социальная синергетика и акмеология / В.П. Бранский, С.Д. Пожарский. - СПб.: Политехника, 2002. - 476 с.

6. Вершловский С.Г. Социализация взрослых: Учеб. пособие / Л.А. Башарина, Л.В. Бродянская, С.Г. Вершловский [и др.]; УПМ. - СПб.: СпецЛит, 2002. $-270 \mathrm{c}$.

7. Колин К.К. Информация и культура. Введение в информационную культурологию / К.К. Колин, А.Д. Урсул. - М.: Изд-во Стратегические приоритеты, 2015. -288 c.

8. Сухобская Г.С. Понятие «зрелость социально-психологического развития человека» в контексте андрагогики // Новые знания. - 2002. - №4.C. $17-20$.

9. Тульчинский Г.Л. Самозванство. Феноменология зла и метафизика свободы. - СПб.: Изд-во РХГИ, 1996. - 412 с. 
10. Урсул А.Д. На пути к опережающему образованию // Вести. Челябинская гос. академия культуры и искусств. - 2012. - №3. - С. 130-133.

11. Шопенгауэр А. Избранные произведения / Сост.; автор. вступ. ст. и примеч. М.С. Нарский. - М.: Просвещение, 1993. - 479 с.

Чекин Илья Анатольевич - канд. пед. наук, заведующий кафедрой ФГКОУ ВО «Санкт-Петербургская академия Следственного комитета Российской Федерации», Россия, Санкт-Петербург.

Chekin Ilia Anatolievich - candidate of pedagogical sciences, head of the department FSEI of HE "Saint-Petersburg Academy of Investigative Committee of the Russian Federation", Russia, Saint-Petersburg. 